\title{
A cautionary tale
}

\author{
Madhouse: a tragic tale of megalomania \\ and modern medicine \\ Andrew Scull \\ Princeton: Yale University Press, 2005 \\ 349 pp \$37.50 (cloth) ISBN: 0-300-10729-3
}

M ore than any other medical specialty, psychiatry is prey to groundless theory; I say this as one who practises in the field. Our patients show no objective signs of abnormality, and despite our rhetoric there is no evidence that any psychiatric disorder is biological. Emotional uproar, tragedy, wild accusation and despair are still the stuff of our everyday work. And yet, being doctors, we hunger for "real" diseases to grapple with, diseases that will yield up biological causes, thus offering hope for specific treatments and definitive cures. From psychobabble, we've moved on to biobabble.

This longing to treat disorders with a physical substrate makes us vulnerable to dangerous nonsense such as insulin coma treatment, lobotomies and theories of chemical imbalance. It is this vulnerability that inspired sociologist Andrew Scull to write this cautionary tale, the strange story of Dr. Henry Cotton.

Cotton was superintendent of the New Jersey State Hospital from 1907 until 1930. During his tenure he became enthralled by the idea that madness was caused by hidden foci of infection - an idea that, although on its deathbed, was still around when I was a medical student. Diligent eradication of such infections would, Cotton thought, wipe out the scourge of mental illness. He had the support of his profession, especially his mentor, Adolf Meyer, chief of psychiatry at Johns Hopkins Medical School.

Cotton's convictions led him to radical intervention: he treated all patients by surgically removing every potential site of infection. Teeth, tonsils and the colon were his favourites, but the spleen, uterus and bladder were also suspect. His surgical death rate was scandalously high - hundreds died and, contrary to his own claims, cures were uncommon.

Adolf Meyer was commissioned to investigate, and assigned this job to his most brilliant student, Phyllis Greenacre. Her findings were devastating. It is a sad fact that Adolf Meyer suppressed her report: medical solidarity had gone mad.

How is it that the medical establishment could have been so easily fooled? fully propagandized treatment, antidepressants, does anything.

This is what befuddled Henry Cotton. Some patients probably improved, but time showed he had cured no one. His discouraging long-term outcomes are echoed by modern studies that conclude that, in the long term, schizophrenic patients treated with neuroleptics do no better than those who don't get them. Never mind that many studies are flawed: if the results with and without neuroleptics aren't different enough to be easily distinguished, we know the treatment isn't doing much. But, in the short term, because they suppress unattractive behaviour, treatment with neuroleptics makes physicians and family members feel more comfortable; we feel we are doing something, even though the longterm effects should cause us disquiet.

\section{From psychobabble, psychiatry has moved on to biobabble.}

Think of bloodletting, purges, diets, mountain air, mustard plasters, magnetism, sexual abstinence - you name it, someone has recommended it. In this age of evidence-based medicine, we are presumably less vulnerable except in psychiatry. Because we have nothing objective to study and measure, we rely on patients' opinions of whether our treatments work. But even a questionnaire (a trick that makes us think that, like real doctors, we have a "test") leaves us at the mercy of the placebo effect. We can't produce objective proof that even our most success-
When we are too enthusiastic, we doctors make errors: in a state of furor therapeuticus, as a precautionary measure, Henry Cotton removed teeth from members of his own family. Curb your enthusiasm, I say. Medical sobriety trumps medical passion every time. Treat yourself to Andrew Scull's new book, a fast-paced thriller that reminds us that fervour can lead us astray.

\section{Gordon Warme}

Centre for Addiction and Mental Health Toronto, Ont. 